\title{
A EXPERIÊNCIA DA DOENÇA: UM TOCAR DO EXISTIR
}

Christine Delory-Momberger

\section{RESUMO}

A experiência da doença põe em um "fora da vida", um "fora de si" que revela a fragilidade de nossas construções biográficas e submete nossos apegos e nossas "aderências" à experiência de um existir que abre o "eu" a um espaço de alteridade de si mesmo, de incerteza e de transformação. Este "tocar do existir" operando na doença é abordado através de dois artistas, uma fotógrafa e um escritor, e da experiência criadora que desperta em ambos.

Palavras-chave: Experiência da doença. Viver/existir. Transformação. Criação.

\begin{abstract}
THE EXPERIENCE OF THE DISEASE: ONE TOUCH OF EXISTENCE

The experience of the disease leads to an "out of life", an "out of mind" that reveals the fragility of our biographical constructions and submit our attachments and our "adhesions" to the experience of an existence that opens the "self" to a space of alterity, uncertainty and change. This "touch of existence" operating in the disease is approached by two artists, a photographer and a writer, from the creative experience that awakens in both.
\end{abstract}

Keywords: Illness Experience. Live/exist. Transformation. Creation.

\section{RESUMEN}

\section{LA EXPERIENCIA DE LA ENFERMEDAD: UN TOQUE DEL EXISTIR}

La experiencia de la enfermedad pone en un "fuera de la vida", un "fuera de sí" que revela la fragilidad de nuestras construcciones biográficas y somete nuestros apegos y nuestras "adhesiones" a la experiencia de una existencia que abre el "yo" a un espacio de alteridad de sí mismo, de incertidumbre y el cambio. Este "toque de la existencia" que opera en la enfermedad es abordado por dos artistas, una fotógrafa y un escritor, y la experiencia creativa que despierta en ambos.

Palabras clave: Experiencia de la enfermedad. Vivir/existir. Transformación. Creación.

* Doutora em Antropologia (EHESS-Paris). Professora de Ciências da Educação na Université Paris 13 Sorbonne Paris Cité. Fundadora da Universidade Aberta "Sujet dans la Cité (UOSC)" e presidente do Collège International de Recherche Biographique en Éducation (CIRBE). christine.delory@lesujetdanslacite.com 


\section{Introdução}

Pois, existir é literalmente 'estar fora' (diz o latim: ex-sistere). Será preciso dizer fora de que. Será preciso dizer aqui de que estar fora para abrir viver ao seu desenvolver. (JULLIEN, 2016, p. 11, grifo do autor).

Sempre a doença surge como de imprevisto; ela não chega, não se insinua, mesmo se suas premissas são insidiosas, imprecisas, ainda não manifestadas ou negadas, ela aparece, e, de repente, ela está aí. É o médico que anuncia isto, e a radiografia ou outros exames médicos que o comprovam. E a vida bascula. Também pode ser um acidente, grave, de consequências ainda incertas, ou mais leve, mas que vai prejudicar o cotidiano durante um tempo ainda indefinido. É um buraco que se abre, um vazio que vai ter de ser preenchido, uma errância no sentido de uma vida que quer ser reencontrada. A gente se agarra, se reconforta, se preocupa, se assusta, espera, não se resigna. Queremos acreditar que será apenas uma passagem, uma zona sem cobertura no fluxo de uma atividade que preenche os dias, os satura, os sobrecarrega e da qual vamos querer por vezes escapar. E a doença, a deficiência estão aí e tudo fica abalado. Ficamos em um "fora" que não nos interessa, que não é mais "si", queremos retomar o fio dos dias que ainda ontem, para alguns de nós, parecia infernal, queremos estar novamente "dentro", não queremos ser postos de lado do que chamamos de "nossa vida".

Como lidar com a "intrusa", a hóspede que não convidamos, que não queríamos receber mas que foi ficando, para a qual damos um nome, o nome da doença, da ferida, da deficiência. Agora precisamos aprender a compor com ela, encontrar as palavras para falarmos dela, "tratá-la bem" ao tratarmo-nos. Que tempo é este que se instaura então, o tempo da doença. Será um tempo da impotência, um tempo morto? Será o tempo de uma experiência que, tocando o corpo, nos faz experimentá-lo de outra forma, em sua fragilidade e seus limites, e nos ensina nossa finitude? E se for, qual(is) o(s) caminho(s) aberto(s) então por essa aprendizagem? Será um tempo desligado do tempo que ritmava nossa vida social, familiar, afetiva, que o continha e nos mantinha em um viver que fazia as vezes de um existir?

\section{A doença, o viver, o existir}

A doença impacta o corpo antes de qualquer outra coisa, ela o impede, o incomoda, o faz sofrer, o deforma, o diminui, o enfraquece. $\mathrm{O}$ corpo não é mais o que era. Ele está desorientado nos começos da doença. São as idas e voltas para os consultórios dos médicos, os chás de cadeiras nos corredores de hospital, a espera dos diagnósticos médicos. São os desconfortos de um mal cujos ritmos desconhecemos, que lança seus picos de dor, que lancinante se instala. Primeiro temos esta experiência. E depois, logo em seguida, "não somos [...] mais que uma flutuação, uma suspensão de estranhamento entre estados mal identificados, entre dores, impotências, fraquezas. Referir-se a si mesmo tornou-se um problema, uma dificuldade ou uma opacidade" (NANCY, 2010, p. 88). A doença pede atenção, cuidado. Ela desvia o curso dos dias e das noites, dobra-o segundo sua exigência, modula-o na imprevisibilidade de sua progressão, nutre-se do sentimento de vida para não ceder o lugar àquele da morte, embora este se torne presente. E "saímos perdidos desta aventura. Não nos reconhecemos mais; mas 'reconhecer' não tem mais sentido" (NANCY, 2010, p. 39). Como pensar a doença ou o acidente quando the acontecem, literalmente caem em cima de você, quando estamos mergulhados na experiência da dor, do medo que esta suscita, da esperança de uma remissão ou de uma cura. Estamos então totalmente em exterioridade, esperamos o que vai dizer o médico, o cuidador, procuramos o que se conta na Internet, frequentamos os fóruns para ligar essa experiência a uma comunidade, nos persuadimos que esse algo que nos acontece não ocorre apenas conosco e que outros o superaram. Então conseguiremos também. E logo ficamos novamente duvidando, vacilamos, não sabemos mais: "Na doença, nos descobrimos tanto quanto nos perdemos e nos tornamos outro" (ZAOUI, 2010 , p. 62). Ficamos sozinhos, abandonados por um corpo que se dissocia de uma consciência de si que confortava um viver, que tinha seus altos e baixos mas que andava. Sim, andava ainda assim e agora nada está andando mais. A linha do horizonte fica desfocada, avançamos com radar, com o falar dos médicos, com os sinais do mal. 
Obviamente não é a mesma coisa de estar com AIDS ou com câncer, ou estar de repente com uma doença autoimune, ou de sofrer um acidente que quebrou nossos ossos e do qual vamos nos recuperar mesmo ficando com marcas para toda a vida, ou passar por uma cirurgia invasiva que será seguida por uma longa convalescência; mas o que há de comum entre todos esses casos é o estado de estupefação e a interrupção de uma relação a um curso de nossa vida, que fazia com que a levássemos, que este surgimento provoca. E como depois, e isso depende das pessoas e do nível de gravidade da doença, ficamos com este espanto, "este encontro com um imprevisto que nos apanha e nos violenta em vez de nos ensinar" (ZAOUI, 2010, p. 72). Precisamos, então, nos desvencilhar, sair deste vivido imediato, desta experiência que está se fazendo, deste Erlebnis que, em toda a força de seu domínio, não deixa lugar ao recuo da reflexividade, à retração que faz com que se torne uma experiência do vivo, uma Erfahrung (DELORY-MOMBERGER, 2014) que vai nos construir, nos reconstruir enquanto sujeito, e que a doença vai então tornar-se este "outro andamento da vida" (GANGUILHEM, 2009).

Mas nessa busca, o sentido na maioria das vezes se faz esperar... Por que eu? O que eu fiz que era contrário à minha saúde? Será que fumei demais, que bebi demais, que tive encontros arriscados que me fizeram desviar? Será que me alimentei mal, que trabalhei demais, sem me poupar? Será que eu tinha um problema que vinha me roendo e que eu não reconhecia? Sim, é verdade que eu já não estava muito bem, por vezes eu estava com angústias, com alguma dificuldade, mas estava vivendo, eu tinha aprendido a viver com isso tudo e não tão mal afinal, visto retrospectivamente... Mais perguntas ainda me chegam, me pesam, me deixam atolada(o)...

É o tempo das oscilações entre o assombro causado pela doença, a desesperança, a esperança e a vontade de uma retomada de um curso de vida cuja realidade ainda desconheço, que vou construir nas limitações do tratamento, de uma perturbação permanente com a qual vou ter de viver, na qual vou desenvolver uma atividade, o que Catherine Tourette-Turgis (2015) chama atividade de "manutenção de si em vida". "Ficar doente, aprender sua doença, é sempre tanto acolhê-la quanto recusá-la, tanto deixá-la nos atravessar quanto estorvá-la com todas as suas forças, tanto submeter-se quanto revoltar-se contra" (ZAOUI, 2010, p. 73). Entrar, portanto, em uma "distância" (JULLIEN, 2012), não opor a doença à saúde, abrir-se um espaço nela, reconhecer que a saúde e a doença são de fato ligadas em um processo do vivo, que o balanço que vai de um lado ou do outro é o balanço da própria vida, que o sentimento de aniquilamento que a ideia de uma morte possível provoca não é contrário à vida, que o pior pode tocar o melhor mesmo se isto foge de início à lógica. É na distância que pode advir o momento epifânico do sentimento de um existir que me fazia falta, de tão atolado que eu estava no viver, atarefado em manter minhas "aderências" (JULLIEN, 2016), meus vários elos pessoais, sociais, profissionais, mesmo se me constrangiam, que eu sentia muito bem que eu tinha que aliviar-me. Mas por receio que tudo desmoronasse, eu segurava, sustentava o edifício de um eu no qual eu me reconhecia, embora por vezes eu me encarasse como pode acontecer na frente de um espelho manchado, com o estanho empretecido em vários lugares; colocava sentido ali porque viver sem colocar sentido não funciona. Tudo se desarticula, se espalha e nos perdemos, nos esgotamos tentando reunir pedaços para formar uma figura, uma figura que seria um si possível. A doença abre uma fenda, redistribui a geografia íntima e é nesta distância de um novo território que se situa a chance de uma transformação de si através da experiência do que é um existir.

Faz-se necessário agora dizer o que é o viver e sua tensão com o existir, e forçosamente falaremos também do morrer. Viver, se o considerarmos do ponto de vista biológico, é o que faz um corpo no qual células, órgãos, circuitos nervosos e sanguíneos se mantêm em atividade. Viver é uma manutenção do vital. Jean-Claude Ameisen (1999) não opõe a vida à morte, ele as interliga em um processo no qual a vida seria o resultado, sempre provisório, de uma atividade de certas células - "os protetores" - em impedir outras - "os executores" - de se auto-aniquilarem e por isso mesmo porem o organismo todo em perigo. ${ }^{1}$

1 "É a partir de informações contidas em seus genes que nossas células produzem os 'executores' capazes de precipitar o fim delas e os 
A vida seria, portanto, dependente de um sistema orgânico de vigilância interna de sinais celulares anunciando uma autodestruição. Cada célula é assim alternadamente "protetor" ou "destruidor”, não há célula boa ou célula má, elas são partes de um processo no qual a vida e a morte são unidas. Assim, elas produzem um viver que não é um estado - e é o que diz o uso do verbo viver em relação ao substantivo vida -, mas um movimento de andanças imprevisíveis, movido por uma lógica que foge a toda lógica. O morrer acontece dentro do viver, ele é produzido ao longo das "transformações silenciosas" (JULLIEN, 2009) que nos moldam, de uma "escultura do vivo" que se faz pelas sucessivas formações e desaparecimentos celulares, verdadeira criação de si na qual se pode imaginar que o desejo de viver, em sua complexidade e suas contradições, anima este arranjo que mal começamos, senão a compreender, pelo menos a perceber.

Há portanto algum viver além de um coma adiantado em um corpo que não está mais reagindo, sustentado por um coração que está batendo artificialmente. ${ }^{2}$ Há algum viver dentro do morrer que o atravessa.

O viver, para ancorar-se no vivo, se nutre do que François Jullien (2016) chama de "aderências", que ele distingue do termo "adesões". As aderências não são objeto de decisões, elas se formam à medida de elos sociais, familiares e profissionais, de encontros, elas são "a capacidade de permanecer ligado a uma superfície" (JULLIEN, 2016, p. 44): aderências a pessoas encontradas, a grupos aos quais pertenço, a convicções que tive um dia, a um estilo que me apropriei. Elas envolvem o ser, dão-lhe o sentimento de um "eu sou" que reconforta, acolhe, mesmo se por vezes restringe, sufoca. O eu da aderência é confundido com o eu do existir: "Até onde se estende minha vida eu vou aderindo e 'eu' se solta dela apenas em 'eu'". (JULLIEN, 2016, p. 18, grifo do autor).

'protetores' capazes, por um tempo, de neutralizar estes executores. E a sobrevida de cada célula depende dia após dia de sua capacidade de perceber, no ambiente de nosso corpo, os sinais moleculares emitidos por outras células, que são os únicos sinais que lhes permitem reprimir o desencadeamento de sua autodestruição". (AMEISEN; HERVIEU-LÉGER; HIRSH, 2003, p. 06, grifo do autor).

2 Essa é a posição introduzida na literatura médica em 1959 por dois médicos franceses, Pierre Mollaret e Maurice Goulon, indicando que a morte só pode ser definitivamente declarada quando há parada das funções cerebrais.
O existir começa quando o eu se extrai de seu atolamento em suas aderências, quando ele se desvencilha de suas amarras, de suas certezas, de suas posses materiais e mentais, para avançar-se em um desconhecido dele mesmo, para pôr-se como sujeito. O "eu" experimenta o existir em travessias da vida que o surpreendem com sua violência, como pode fazer a doença quando ela irrompe. O véu é levantado do artefato do "eu" das aderências que racham, se fissuram e perdem algo de sua compacidade. O "eu" está "fora de", fora do que ele acreditava ser a vida, mas que era apenas a interiorização de uma forma social, de um óbvio cultural, de uma moda. A distância abre-lhe este novo território. A vida, quando assombrada pela doença, pressente suas finitudes, a morte torna-se tangível. Não encontramos mais o sentido, temos de procurá-lo em outros lugares, aventurarmo-nos em incertezas, ousarmos enfrentar a nudez do ser, nos desvencilharmos dos tentáculos das aderências para, apesar de tudo, ficarmos novamente em pé. A distância é "uma figura [...] de perturbação que faz aparecer, por isso, não uma identidade, mas o que eu chamaria de uma fecundidade" (JULLIEN, 2012, p. 35). A distância abre um espaço renovado, pois ela não opõe a vida, a morte, o viver e o existir, ela coloca-os em tensão de reciprocidade produtiva em um entre. $\mathrm{Na}$ distância, há o sujeito que segura o entre, atarefado finalmente em si mesmo em uma reflexividade, uma inteligibilidade, um autorreflexo (JULLIEN, 2012), levando a inflexões, a transformações. Na distância, há este outro que se ergue como sujeito e que "ao salvar da asfixia de si, do autofechamento, mantém o 'si' em progresso" (JULLIEN, 2012, p. 78, grifo do autor). Neste espaço de alteridade de si com si, os horizontes ampliam-se, circulações acontecem, vias descobrem-se, mostrando o caminho para um eu em subversão, em transformação, um eu na obra de si.

\section{Estelle Lagarde e a travessia imprevista}

Escolhi falar de dois artistas marcados pela experiência da doença: uma é Estelle Lagarde, fotógrafa e arquiteta, e o outro, Frédéric Badré, escritor: a primeira teve um câncer do seio e o 
segundo uma doença neurodegenerativa irreversível. Duas travessias tensas, árduas; para uma a remissão estava possivelmente no horizonte, para o outro a degenerescência progressiva não tinha saída.

Estelle Lagarde é uma jovem mulher de trinta e quatro anos quando ela fica sabendo que tem um câncer do seio. Primeiro, é uma bolinha pontuda que não desperta preocupação e para a qual os médicos só prestam atenção quando ela toma o jeito de um tumor maligno. A fulgurância da progressão do mal aniquila Estelle Lagarde e ao mesmo tempo provoca sua raiva. O diagnóstico soa como um veredito de morte. Ela procura por todos os casos de pessoas desaparecidas em seu entorno, a mãe de seu companheiro, seu ex-noivo. Reconfortam-na, o câncer tem boas perspectivas de cura hoje, ela se exalta: "Uma vez que tiraram seu seio, queimaram sua pele, fizeram seu cabelo cair, colocaram um seio falso em você, você está curada!" (LAGARDE, 2010, p. 16).

Então começa para ela a travessia imprevista. Ela se questiona, anda em círculos em seus questionamentos: "Por que eu? Como minhas células chegaram a ser tão anárquicas?". Ela pesa o pró e o contra: "Eu como balanceado, pratico uma atividade física razoavelmente regular, não há nenhum antecedente direto na minha família". Ela devia ter escapado. Mas "é verdade que [...] não tive filho, e não comia orgânicos, e fumava e bebia ocasionalmente, e vivo em uma cidade grande poluída pelos carros e pelas ondas de todo tipo" (LAGARDE, 2010, p. 18).

A preocupação atormenta-a, ela vai de exames médicos em consultas até ter seu itinerário: será uma cirurgia seguida de uma quimioterapia e de uma radioterapia. Ela fica suspensa, licença médica, angústias, emoções, estados de alma contraditórios, impressão de viver uma vida pelo avesso, ela quer estar sozinha e se sente perdida sem os familiares e amigos íntimos. Ela deixa a beira de uma vida com seus pontos de referência de família, de amigos e de profissão, para deixar-se ir à deriva no desconhecido da doença. Então, ela decide acompanhar a si mesma neste percurso que ela não quis, ela adquire uma câmera fotográfica de médio formato que coloca em um tripé e que não sairá de seu estúdio durante os longos meses de seu tratamento, e põe-se a fazer dela mesma uma série de autorretratos $6 \times 7$. Ela também escreverá um diário que pode ser encontrado no livro $A$ Travessia Imprevista. Adenocarcinoma em alternância com as fotografias. Ela escolhe a fotografia tradicional embora trabalhe com fotografia digital "por sua capacidade de conservar o mistério até a revelação do filme" (LAGARDE, 2010, p. 64).

A imagem latente é sua imagem, seu corpo revela-se em suas transformações, talhado pela tumorectomia, ferimento de uma guerra que ela não escolheu travar: envolto em faixas estreitas; a cabeça presa em uma roupa apertada demais da qual ela não consegue sair; com sua cabeça careca; amarrado na cadeira médica, os braços oferecidos às transfusões; os pulsos presos em cordas amarradas com uma fotografia de uma boneca sem cabelo como pano de fundo; o busto escaneado, listrado de preto; as mãos segurando os cabelos que caem aos tufos; o corpo totalmente nu e sem pelos; ou fantasiado com um vestido do século XVIII; diante de um bolo de aniversário, o dela; as mãos mergulhando em um vaso redondo no qual erram aranhas de plástico; o corpo novamente martirizado, transformado em campo de tiro pelos pontos desenhados ao redor do seio para a radioterapia; o corpo em frangalhos; o corpo segurando um brinquedo-esqueleto e também duas mãos entrelaçadas, a dela e a de seu companheiro; a cabeça cheia de cabelos renascendo; novamente sua mão levantando, desta vez um copo para brindar. A vida recomeçando. "Não ter medo da morte. Sem a morte, a vida não existe" (LAGARDE, 2010, p. 36).

A câmera fotográfica abre-lhe esse espaço incerto da doença, assombrado pela morte, pelos medos, pela solidão. Por seu ato de criação, Estelle Lagarde segura o entre, desloca-se na distância. Ela faz autorretratos dia após dia, retrata-se em seu desamparo, em sua dor, encena-se com trajes de fantasia, em posturas exageradas; ela não tem mais imagem, ela tem mil imagens que vão e vêm, que lhe são estranhas e familiares, transitórias e voláteis. Ela soltou-se de suas aderências, ela é um corpo na doença, ergue-se, ela existe. Voltará de sua travessia com uma base diferente: "A vida também fez seu trabalho. Primeiro a odiei. "Depois ela se infiltrou em mim, e nunca lhe dei tanta importância”. (LAGARDE, 2010, p. 88).

Um pouco depois, ela terá um filho. 


\section{Frédéric Badré e a metamorfose}

O mal veio por pequenos saltos, tremores musculares nos braços, faltas de fôlego repentinas, a impossibilidade de emitir o assovio estridente habitual para chamar o cachorro. Frédéric Badré pensava: "Estranho!", e depois continuava fazendo as coisas de sua vida: escrever, pintar, ler, brincar com os filhos, amar sua mulher, encontrar seus amigos escritores, conversar sobre literatura, ouvir música. Distúrbios da elocução já incômodos levam-no para o hospital Saint-Joseph para fazer todo tipo de exames. Ele conforta-se: "Compreender é curar-se" (BADRÉ, 2015, p. 14).

E vem o veredito: ele está acometido por uma doença neurodegenerativa, a ELA. ${ }^{4} \mathrm{E}$ vem o assombro: "Em um tempo vindouro, a única parte propriamente humana que me restará será a cabeça [...] Visão de apocalipse!” (BADRÉ, 2015, p. 18).

Ele faz seu exame de consciência: "De quem é a culpa? Houve em algum momento de minha existência um delito? Um evento desencadeador, sem o qual eu não estaria com a ELA? Ou seria mais o caso de examinar todos os meus hábitos? Em especial os maus hábitos?" (BADRÉ, 2015, p. 31).

Ele não sabe mais, busca razões, certezas, outros apoios em seu corpo, mas tudo se despedaça. Embrenha-se então "na floresta escura" - este será o título da primeira parte de seu livro A Grande Saúde -, zona assombrada por todas as ameaças, por todos os perigos, pela morte. As falhas progressivas de seus músculos privam-no aos poucos de autonomia e levam-no a um retraimento de sua vida social; ele deixa o lugar para um outro que se apossa dele, outro corpo que se torna seu corpo e ele constata: "Uma parte de mim se torna animal." (BADRÉ, 2015, p. 102). Ele vê-se como um monstro e retira-se do mundo, extrai-se de seu viver. Neste pesadelo, lembra-se de Gregor Samsa e de sua "metamorfose", romance fantástico de Kafka - e este será o título da segunda parte do livro -, em "monstruoso verme" (Ungeziefer).

Uma manhã, Gregor acorda em seu novo corpo

3 Frédéric Badré é escritor e pintor. É autor de uma biografia de Jean Paulhan e do ensaio O Futuro da Literatura.

4 "A esclerose lateral amiotrófica é uma doença central do sistema nervoso. Os neurônios motores não respondem mais às ordens enviadas pelo cérebro. Destroem-se aceleradamente e os músculos atrofiam-se, levando rapidamente à paralisia" (BADRÉ, 2015, p. 19). desajeitado de inseto no apartamento da família, tenta localizar-se, comunicar-se com seus familiares, fazer-se reconhecer, mas tudo é em vão; o nojo diante da estranheza de sua aparência, a inconveniência no espaço que seu corpo representa colocam-no na margem, no refugo. Frédéric Badré vê nele uma potência:

Gregor encontra seu destino quando se torna escaravelho. É nessa forma estranha que podemos enxergá-lo como um artista genial. Sua vida torna-se essencialmente contemplativa. Seu gênio desabrocha em uma neutralidade silenciosa, aparentemente inativa, e provoca os estragos de uma arma de destruição em massa. $\mathrm{O}$ conforto burguês, a respeitabilidade social, a tranquilidade dos dias monótonos, tudo explode em pedaços! (BADRÉ, 2015, p. 109).

Frédéric Badré reconhece-se no personagem, agora está como ele retraído, podendo participar apenas interiormente das conversas, por estar impedido de falar de maneira compreensível. Lança frases que não saem de sua boca, não mexe mais seu corpo esclerosado senão em sua mente, em seus sonhos, em sua imaginação, salta, rodopia, ergue-se. Ele deixa vir seus familiares e amigos a seu encontro: "Cada um acha a relação que lhe convém com a doença e, consequentemente, comigo." (BADRÉ, 2015, p. 143). Abandonou o viver pelo existir, soltou-se de suas aderências e abriu a distância pelo milagre da metamorfose. Vive imóvel, tomado na intensidade da criação, existe na escuta da música, no olhar para a pintura, na leitura. "O antídoto [...], o meio para manter-se acordado, a grande saúde tem por nome literatura." (BADRÉ, 2015, p. 106). É o caminho para "o eco das luzes", título dado à terceira parte do livro. Frédéric Badré aprendeu a viver com a doença, "esta fera na espreita de qualquer baixa de atenção para te agarrar na garganta" (BADRÉ, 2015, p. 164). Entrou em um estado de abandono de si, com uma lucidez perfeita, exatamente como certos artistas que ele admira, ele encontra-os na luz, é seu eco, está agora muito presente.

\section{Final}

Existir, uma aprendizagem que a doença nos impõe. É preciso perguntar-se se não temos de falar de "grande saúde" dos doentes. Sua saúde 
é um trabalho de todos os instantes, uma "manutenção de si em vida", um trabalho biográfico que reveste para cada um uma forma singular, que dá a cada um deles um saber que passa por um melhor conhecimento de si, de seus limites físicos e mentais, que faz antecipar as falhas, calcular os riscos, organizar e reorganizar o cotidiano. Atentos a eles mesmos, aos outros e aos próprios entornos, os doentes avançam em uma distância que cada um constrói, na qual cada um coloca as coisas que se tornaram essenciais, na qual a vida e a morte estão ligadas. A saúde não é uma entidade abstrata, é nutrida de fragilidades, de medos, de reincidências, de acidentes, ela vive das experiências, dos recursos e das forças que ela vai buscar. A grande saúde ultrapassa a ideia de conceito comum da "boa saúde" como um equilíbrio do corpo a ser mantido para proteger-se da morte, desvencilha-se das contingências, das aderências para tocar um essencial da vida, um existir.

\section{REFERÊNCIAS}

AMEISEN, J.-C. La sculpture du vivant. Le suicide cellulaire ou la mort créatrice. Paris: Seuil, 1999.

AMEISEN, J.-C.; HERVIEU-LÉGER, D.; HIRSCH, E. Qu'est-ce que mourir? Paris: Le Pommier, 2003.

BADRÉ, F. La grande santé. Paris: Seuil, 2015.

CANGUILHEM, G. Le normal et le pathologique. Paris: PUF, 2009.

DELORY-MOMBERGER, C. De la recherche biographique. Fondements, méthodes, pratiques. Paris: Téraèdre, 2014.

JULLIEN, F. Les transformations silencieuses. Paris: Grasset, 2009.

JULLIEN, F. L'écart et l'entre. Leçon inaugurale de la chaire de l'altérité. Paris: Éditions Galilée, 2012.

JULLIEN, F. Vivre en existant. Une nouvelle éthique. Paris: Gallimard, 2016.

LAGARDE, E. La traversée imprévue. Adénocarcinome. Paris: La Cause des Livres, 2010.

NANCY, J.-L. L'intrus. Paris: Éditions Galilée, 2010.

TOURETTE-TURGIS, C. L'éducation thérapeutique du patient. La maladie comme occasion d'apprentissage. Louvain-la-Neuve: de Boeck, 2015.

ZAOUI, P. La traversée des catastrophes. Philosophie pour le meilleur et pour le pire. Paris: Pocket, 2010.

Recebido em: 05.03.2016

Aprovado em: 09.06.2016 